\title{
Multi-scale effects on the hydraulic behaviour of a root-permeated and compacted soil
}

\author{
Alessandro Fraccica ${ }^{1,2}$, Enrique Romero, ${ }^{1, *}$, and Thierry Fourcaud ${ }^{2}$ \\ ${ }^{1}$ Universitat Politècnica de Catalunya, CIMNE, Barcelona, Spain \\ ${ }^{2}$ AMAP, CIRAD, CNRS, INRA, IRD, Univ. Montpellier, Montpellier, France
}

\begin{abstract}
While roots have been generally proved to be beneficial to soil mechanical behaviour, different and counterposed results have been found when investigating their effects on soil hydraulic response. Roots affect the hydro-mechanical and chemical properties of soils at different scales. In this regard, the paper focuses on studying the macroscopic hydraulic properties of root-permeated and compacted soils considering microstructural features coming from mercury intrusion porosimetry and X-ray micro-tomography. The results are interpreted bearing in mind the influence of the different soil hydraulic states on roots structure and physiology. The analysis of the results shows that roots growing in a compacted soil at low stresses are opening fissures while decreasing micropore volume inside aggregates due to chemical effects. This response has important effects on the hydraulic behaviour of the soil.
\end{abstract}

\section{Introduction and background}

Geotechnical and ecological investigations have usually studied the effects of roots on soil hydraulic behaviour focusing on different aspects of the response. The former studies have paid more attention on the initial state of the soil and the way it affects plant growth. They have been aimed at determining the water permeability and water retention properties [1-5], but often neglecting the effects that the evolution of soil conditions has on the growth and physiology of plants. Geotechnical results have evidenced that soils initially compacted at different states may have opposite hydraulic responses when root-permeated. This in turn depends on the mechanical and structural properties of the root system, which has an impact on its ability to grow and penetrate a confined or loaded porous medium. On the other hand, ecologists and plant scientists have carried out their studies focusing on how the phenomena that occur at the level of the root system and individual roots indirectly influence the macroscopic response of the soil, but poorly considering the evolution of the hydro-mechanical properties of the soil.

Processes such as roots shrinkage and exudation on drying have been characterised by imaging techniques or soil physical-chemical analyses [6-10] and are inducing counterposed effects on soil:

- roots shrinkage on drying contributes to widen the pre-existing interfaces and fissures in the soil and thus is altering its water retention properties and intrinsic permeability;

- mucilage produced by roots during soil drying allows plants remaining in contact with the soil particles but modifies soil chemical properties and clogs pores, and thus locally changes the water retention capacity of the medium.

Recently, there has been several attempts to perform multi-disciplinary studies, in which roots features [11] and growth stages and decay [12] have been used to build empirical correlations and models to describe plant effects on void ratio and, indirectly, on soil hydraulic behaviour. An indirect analysis was done by [13] to correlate root properties with soil structural changes (void clogging and fissures creation). However, there is still not a constitutive framework able to predict the soil hydro-mechanical behaviour considering physico-chemical processes occurring at the root scale and their effects on soil microstructural changes.

With the aim of deepening the above-mentioned knowledge and providing the basis for a hydromechanical constitutive framework for a root-permeated and compacted soil, the present study focuses on:

- quantitatively identifying by different multi-scale and complementary tests, which are the main mechanical and chemical effects induced by a root system growth on soil microstructure and on its hydraulic behaviour;

- studying the evolution of soil microstructure along hydraulic paths on bare and root-permeated conditions.

\section{Materials and compaction properties}

Laboratory studies were performed on a silty sand retrieved at the Llobregat river's delta in Barcelona. Its physical properties are summarised in Table 1 and further detailed in [14]. The same low-plasticity soil was used to build a full-scale embankment currently under monitoring for investigating soil-vegetation-atmosphere interactions

\footnotetext{
* Corresponding author: enrique.romero-morales@upc.edu
} 
[14]. For this study, the retrieved soil has been sieved at $9.5 \mathrm{~mm}$.

Table 1. Soil main physical properties.

\begin{tabular}{|l|c|}
\hline \multicolumn{1}{|c|}{ Soil property } & Value \\
\hline Soil fraction $<2 \mathrm{~mm}(\%)$ & 58.8 \\
\hline Soil fraction $<75 \mu \mathrm{m}(\%)$ & 30.8 \\
\hline Soil fraction $<2 \mu \mathrm{m}(\%)$ & 5.4 \\
\hline Liquid limit $(\%)$ & $29.5-34.4^{a}$ \\
\hline Plasticity index $(\%)$ & $9.6-13.5^{a}$ \\
\hline Density of solids, $\rho_{s}\left(\mathrm{Mg} / \mathrm{m}^{3}\right)$ & $2.65-2.70^{a}$ \\
\hline
\end{tabular}
${ }^{a}[14]$

Eight cylindrical specimens $(150 \mathrm{~mm}$ in diameter and $70 \mathrm{~mm}$ in height) were statically compacted in PVC pots at a water content of $w=15 \%$, matric suction $s=40 \mathrm{kPa}$ and dry density $1.60 \mathrm{Mg} / \mathrm{m}^{3}$ (point ' $\mathrm{A}$ ' in Fig. 1). This compaction state corresponded to a void ratio $e=0.67$, a water ratio $e_{w}=\rho_{s} w / \rho_{w}=0.40$ (i.e., volume of water to volume of solids), and a degree of saturation $S_{r}=e_{w} / e=$ 0.61. Maximum total vertical stress applied on compaction was $100 \mathrm{kPa}$. The soil was compacted at a low energy level (below $240 \mathrm{~kJ} / \mathrm{m}^{3}$ of the dynamic compaction points presented in the figure) and dry of the optimum to have a well-developed double-structure and to create favourable conditions (water and air presence) for roots growth. After compaction and seeding, specimens were wetted at zero vertical stress - without appreciable volume change- to $S_{r}=0.80$ (from point 'A' to 'B' in the figure) to allow plants development. After the roots growing phase, specimens were air-dried under unstressed conditions to reach the initial states for testing between points ' $\mathrm{B}$ ' and ' $\mathrm{C}$ '. For sake of comparisons, bare control specimens were submitted to the same hydraulic stress path.

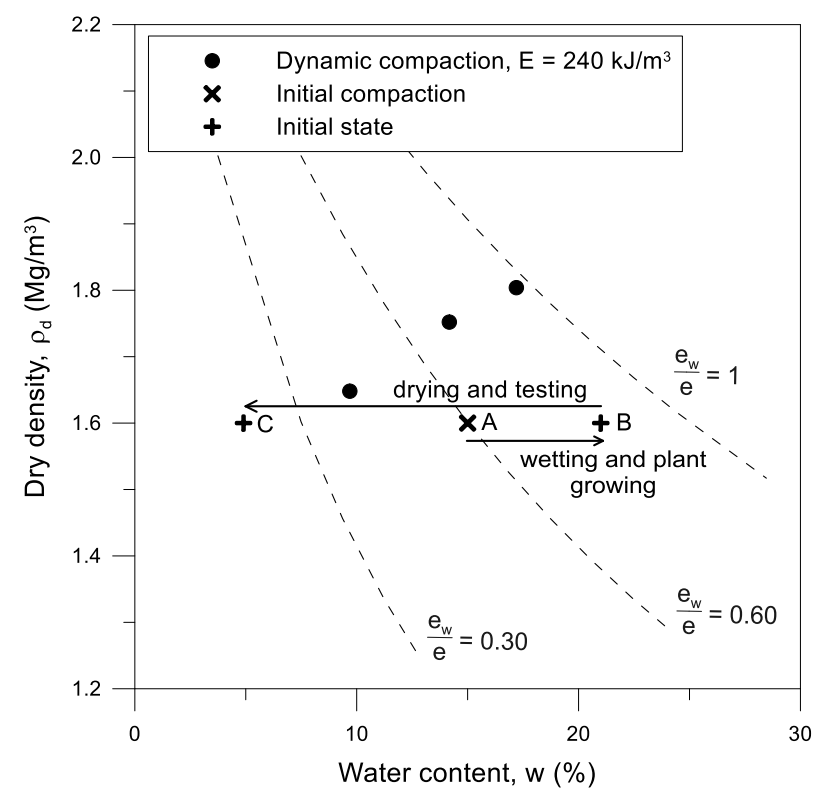

Fig. 1. Compaction plot. Compaction state ' $A$ ' and stress paths followed to set the initial states between ' $\mathrm{B}$ ' and ' $\mathrm{C}$ '.
The turfgrass used for the study is Cynodon Dactilon. This plant is highly resistant to drought $[15,16]$ and water submergence [17]. It also presents a fine roots system and forms shallow branches -stolons and rhizomes [18]organised as a net connecting the different plant individuals. Thanks to its properties, it has been already used in slope stability investigations $[19,20]$.

\section{Multi-scale experimental program}

\subsection{Hydraulic behaviour of the soil}

\subsubsection{Water retention curves}

After roots system full development (roots reaching the bottom part of the pots), three root-permeated and one control pots were used to assess the water retention properties. A ceramic tip tensiometer (T5x, UMS, Germany) was used to measure matric suction up to $200 \mathrm{kPa}$. Water contents were checked by oven-drying soil samples retrieved from pots. During the tests, water contents were evaluated by weight determinations, neglecting any possible change of roots mass (the measurements were done along three weeks). This hypothesis was confirmed by the coinciding final water content measured by oven-drying with the one predicted by mass check. To allow suction equalisation after any drying step, all the pots were placed, for the subsequent 24 hours, in glass desiccators in a temperature-controlled room (at $20 \pm 1^{\circ} \mathrm{C}$ ), as shown in Fig. 2. To check the equalisation process, a sensor measuring temperature and air relative humidity was placed in the glass desiccator. Matric suctions were also measured with a tensiometer installed inside the specimens. Measurements were done along a drying path (from ' $\mathrm{B}$ ' to ' $\mathrm{C}$ ' in Fig. 1) and followed by a wetting path (from ' $C$ ' to ' $B$ ' in Fig. 1). Particular attention was paid to volume change measurements to fully characterise the hydraulic states in terms of void ratio and degree of saturation. Further details of the measurement methodology are explained in [21].

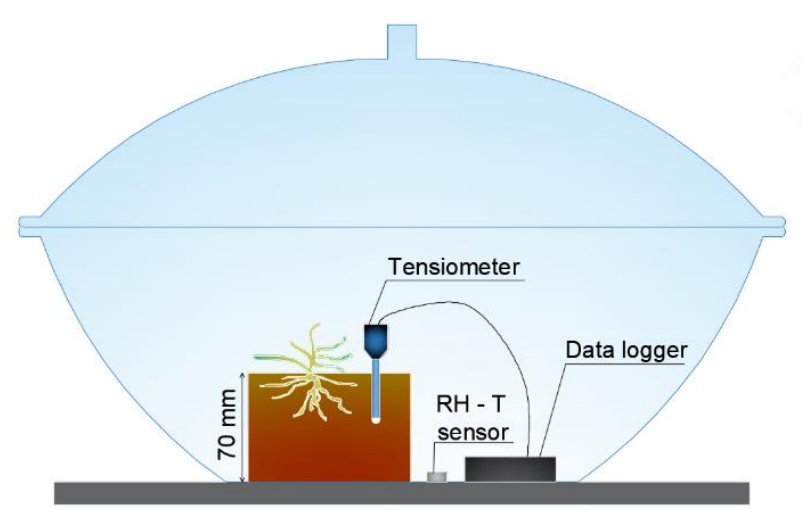

Fig. 2. Glass desiccator used for suction equalisation for vegetated and bare specimens. 


\subsubsection{Soil water permeability}

Large-size oedometer tests results were performed to determine the saturated water permeability under controlled-gradient conditions and within the void ratio range under study. The large oedometer size $(150 \mathrm{~mm}$ in diameter and $70 \mathrm{~mm}$ high) allowed testing the entire specimens compacted with the cylindrical pots previously described.

\subsection{Roots effects on soil microstructure}

The pore size distributions before and after roots growth and at different water contents were determined to study roots microstructural effects on the soil. Two complementary techniques were used: a) mercury intrusion porosimetry MIP (AutoPore IV 9500 Micromeritics Instrument Corporation, USA); and b) Xray micro-tomography (MicroCT V|Tome|X s 240, GE Sensing \& Inspection Technologies GmbH, Germany).

\subsubsection{X-ray micro-tomography}

Thirty-millimetre side cubes, including small root systems, were trimmed from the pots described above to perform X-ray micro-tomography. Spatial resolution was around $36 \mu \mathrm{m}$ and large-dimension pores could be easily distinguishable from the rest of the matrix. Image treatment, including the choice of threshold values to identify voids, roots and solids is explained in [21]. Once roots were excluded from both solid and void phases within the binarised images, soil pore-size distributions were estimated using the plugin "pore-size distribution" of ImageJ [22].

\subsubsection{Mercury intrusion porosimetry}

MIP allowed complementing the X-ray tomography observations and assessing voids ranging from $500 \mu \mathrm{m}$ down to $7 \mathrm{~nm}$. For each water content, cubes were trimmed from the corresponding samples previously scanned by X-ray micro-tomography. Ten-millimetreside cubes were recovered at the soil-roots interface and then freeze-dried prior to testing.

\section{Results and interpretations}

\subsection{Hydraulic results}

Main drying retention results are presented in Fig. 3 for bare and root permeated soils (an extended suction range using vapour equilibrium and psychrometer results is presented in [21], including measurements on other rootpermeated soil replicates). Results are plotted in terms of water ratio $e_{w}$. Within the range measured by the tensiometer and for the same water ratio, the rootpermeated soil presented lower matric suctions compared to the bare soil. This can be associated with a reduction of the air-entry value of the root-permeated soil associated with fissures created between roots and soil interfaces that will be later described. On drying at low stress conditions, with soil and root concurrent shrinkage, these fissures increase in volume as detected by [21].

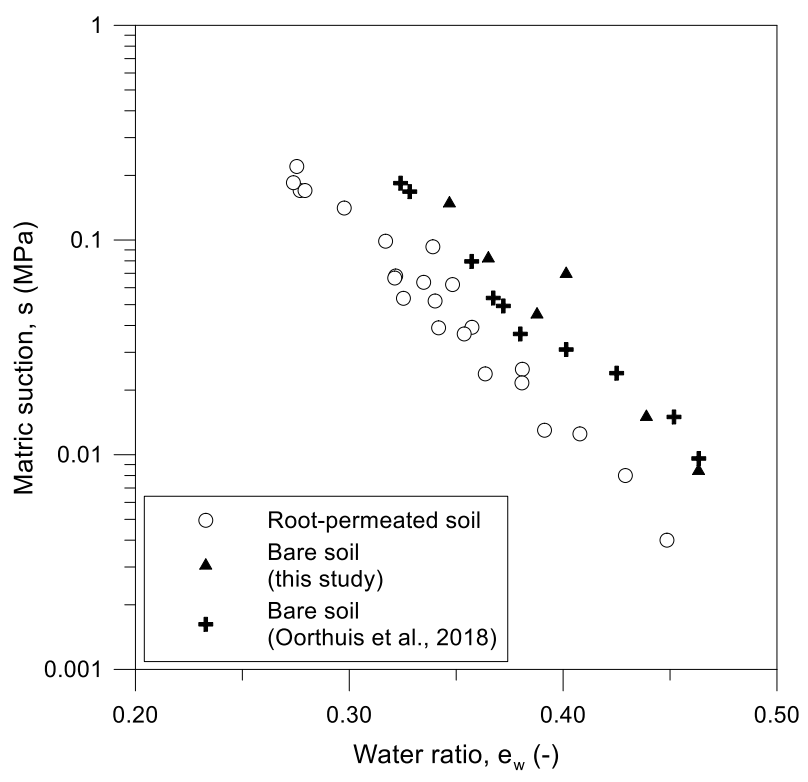

Fig. 3. Main drying results using tensiometer for bare and root permeated soils. Comparison of results obtained for this study and by [14] for the same soil.

Root volume ratio was used as parameter indicating the presence of roots within the matrix: it is computed as the ratio between roots and bulk soil volume. It was evaluated to lie between 0.02 and 0.04 based on X-ray tomography data [21].

Concerning soil water permeability, results are presented in Fig. 4. For the whole void ratio range investigated, root-permeated soil exhibited a higher water permeability with respect to bare soil. Root volume ratio of the tested soils was similar to the values found for the water retention tests. This increase in water permeability at low stress conditions is again associated with the generation of fissures between soil and roots interfaces, as described in the following section.

\subsection{Microstructural features}

Fig. 5 presents a comparison between pore-size density PSD functions -evaluated following [23]- obtained before and after root growth, at $e_{w}=0.33$ and around $e \approx 0.64 \quad\left(S_{r} \approx 0.52\right)$. The curves were obtained by combining MIP and X-ray micro-tomography data.

The interpretation of the different phenomena that have induced the PSDs at the two soil conditions at low stresses is not trivial. To simplify the observations, it was decided to distinguish two main domains within the distribution: one above and one below $100 \mu \mathrm{m}$. The most difficult interpretation was found for porosities lying below this threshold, even when a general micropore volume decrease was generally observed in a rootpermeated soil. Within this range of micropores, distinct and sometimes opposite phenomena are occurring:

- pore clogging by chemical substances,

- pore clogging by roots and roots hair, and 
- micro-voids opening.

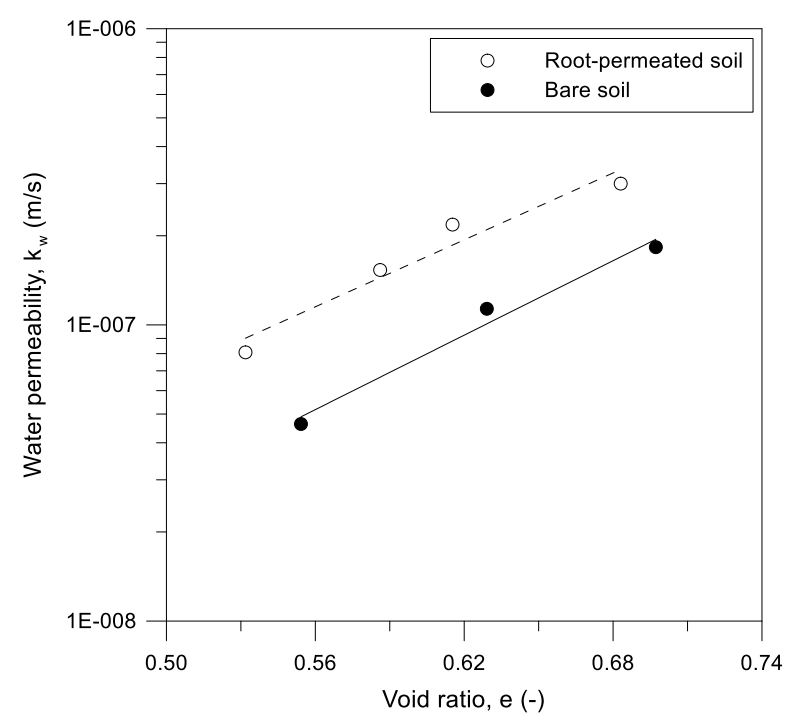

Fig. 4. Water permeability for bare and vegetated soils determined at different void ratios.

As shown in Figure 5 for a root-permeated soil, pores below $2 \mu \mathrm{m}$ tend to decrease in volume with respect to a bare soil. These pores sizes, in fact, cannot be physically penetrated by roots or root hairs (these last are larger than $10 \mu \mathrm{m}$ approximatively [24-26]). So, the impact of the roots on this range of porosity is dominated by chemical effects. The observed phenomenon is explained by the rhizosheaths formation, which is caused by mucilage permeation followed by micropore clogging that induces the bonding of roots and particles as the soil dries $[8,27,28]$.

According to Young-Laplace's equation, pore size reduction by clogging for given water content, physically induces an increase in matric suction. This result appeared to be contradicting the trend observed at the macroscale at low suction values (Figure 3). Nevertheless, chemical effects are also expected to occur, since the surface tension of the liquid within soil zones surrounded by mucilage has been found to be lower than the one for water at $20^{\circ} \mathrm{C}[27,29,30]$.

Another pore volume decrease mechanism for a rootpermeated soil was considered between $10 \mu \mathrm{m}$ and $100 \mu \mathrm{m}$, which was associated with the clogging of some pores by roots and root hairs.

On the other hand, results above $100 \mu \mathrm{m}$-obtained mainly from X-ray image analysis- showed that a compacted root-permeated soil exhibited pore volume increase at low confining stresses. This occurred due to roots inducing fissure opening mainly at the roots-soil interfaces. As shown more in detail by [21] and in rootpermeated soils, macropore volume increased on drying while dominant pore size peaks shifted towards lower pores sizes. This was due to soil and root concurrent shrinkage, along which pre-existing fissures increase in volume. This last effect is explaining macroscopic behavioural features observed on water retention properties (reduction of the air-entry value at low matric suctions observed in Figure 3), as well as on soil saturated water permeability (Figure 4).

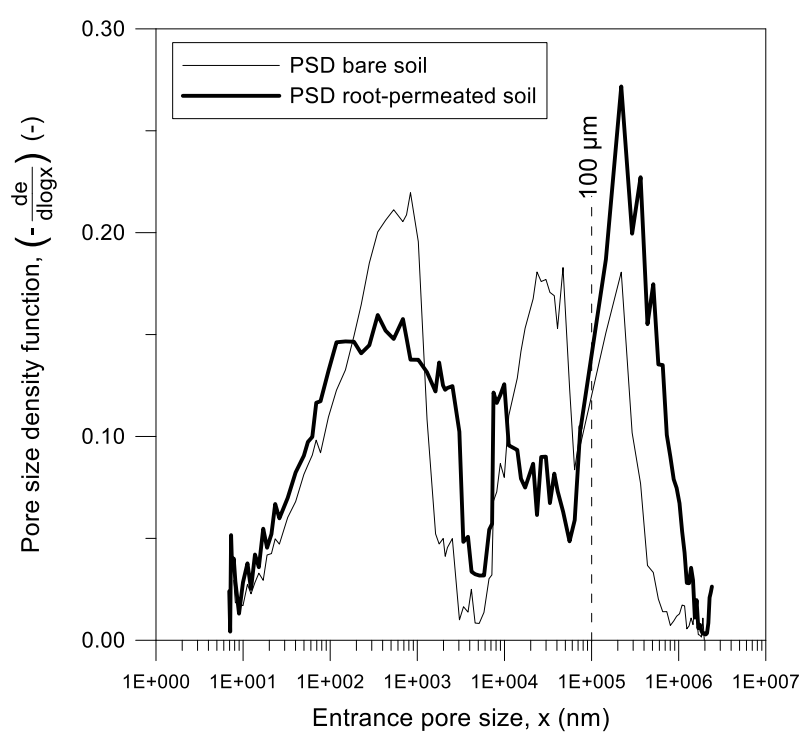

Fig. 5. Pore size distributions obtained by complementary techniques for bare and root-permeated samples.

\section{Conclusions}

This study allowed characterising macroscopic and microscopic effects of roots on a compacted silty sand subjected to low stresses. Relevant phenomena were observed at different soil hydraulic states, thus highlighting the necessity of having an extended overview of coupled processes occurring on soil and roots. On drying, roots are known to produce mucilage that is clogging pores and thus inducing local consequences on water retention properties, suction and chemo-physical properties. Larger roots are fissuring soil, thus creating macropores and preferential paths for water to flow. During desiccation, concurrent drying of roots and soil induce further macropore volume increase that affect the water retention properties. Changes of hydraulic soil properties observed at the macroscale (e.g. air entry value decrease at low matric suctions and soil water permeability increase) were explained based on the observed microstructural features.

The authors wish to acknowledge the support of the European Commission via the Marie Skłodowska-Curie Innovative Training Networks (ITN-ETN) project TERRE 'Training Engineers and Researchers to Rethink geotechnical Engineering for a low carbon future' (H2020-MSCA-ITN-2015-675762).

Micro-tomography scans were performed in the Laboratory of Microscopy and Computed Micro-tomography at CENIEH facilities (Burgos, Spain) with the collaboration of CENIEH staff.

Alessandro Fraccica also wishes to acknowledge the fruitful discussions with the members of TERRE and SMUCPHY projects, as well as with Dr. Vito Tagarelli and Dr. Agustín Cuadrado.

\section{References}

1. J. A. Smethurst, D. Clarke, and W. Powrie, 
Géotechnique, 62, 429 (2012)

2. C. W. W. Ng, A. K. Leung, and K. X. Woon, Can. Geotech. J., 51, 311 (2014)

3. A. K. Leung, A. Garg, J. L. Coo, C. W. W. Ng, and B. C. H. Hau, Hydrol. Process., 29, 3342 (2015)

4. A. K. Leung, A. Garg, and C. W. W. Ng, Eng. Geol., 193, 183 (2015)

5. L. Pagano, A. Reder, and G. Rianna, Can. Geotech. J. (to be published)

6. A. Carminati, D. Vetterlein, N. Koebernick, S. Blaser, U. Weller, and H. J. Vogel, Plant Soil, 367, 651 (2013)

7. X. P. Liu, W. J. Zhang, X. Y. Wang, Y. J. Cai, and J. G. Chang, Tree Physiol., 35, 1343 (2015)

8. A. Carminati, A. B. Moradi, D. Vetterlein, P. Vontobel, E. Lehmann, U. Weller, H. J. Vogel, and S. E. Oswald, Plant Soil, 332, 163 (2010)

9. A. B. Moradi, A. Carminati, D. Vetterlein, P. Vontobel, E. Lehmann, S. E. Oswald, U. Weller, and J. W. Hopmans, New Phytol., 192, 653 (2011)

10. D. Karup, P. Moldrup, M. Tuller, E. Arthur, and L. W. de Jonge, Eur. J. Soil Sci., 68, 57 (2017)

11. C. W. W. Ng, J. J. Ni, A. K. Leung, and Z. J. Wang, Géotechnique Lett., 6, 106 (2016)

12. J. J. Ni, A. K. Leung, and C. W. W. Ng, Can. Geotech. J. (to be published)

13. P. Scholl, D. Leitner, G. Kammerer, W. Loiskandl, H. P. Kaul, and G. Bodner, Plant Soil, 381, 193 (2014)

14. R. Oorthuis, M. Hürlimann, A. Fraccica, A. Lloret, J. Moya, C. Puig-Polo, and J. Vaunat, Water (Switzerland), 10, (2018)

15. N. Adamipour, H. Salehi, and M. Khosh-Khui,
Adv. Hortic. Sci., 30, 141 (2016)

16. R. N. Carrow, Crop Sci. 36, 687 (1996)

17. S. Tan, M. Zhu, and Q. Zhang, Acta Physiol. Plant., 32, 133 (2010)

18. M. Dong and H. de Kroon, Oikos, 70, 99 (1994)

19. F. Chen, J. Zhang, M. Zhang, and J. Wang, Ecol. Process., 4, 3 (2015)

20. A. Garg, J. L. Coo, and C. W. W. Ng, Earth Surf. Process. Landforms, 40, 1631 (2015)

21. A. Fraccica, Experimental and Numerical Study of Soil-Roots Hydro-Mechanical Interactions, Universitat Politècnica de Catalunya; Université de Montpellier, $\mathrm{PhD}$ Thesis (in preparation)

22. B. Münch and H. Lorenz, J. Am. Ceram. Soc., 91, 4059 (2008)

23. E. Romero and P. H. Simms, Geotech. Geol. Eng., 26, 705 (2008)

24. B. Lamont, Plant Soil, 74, 149 (1983)

25. C. Grierson and J. Schiefelbein, Arab. B., 1, 60 (2002)

26. D. Wulfsohn and J. R. Nyengaard, Plant Soil, 209, 129 (1999)

27. D. B. Read, P. J. Gregory, and A. E. Bell, Plant Soil, 211, 87 (1999)

28. M. Watt, M. E. McCully, and M. J. Canny, Plant Physiol., 106, 179 (1994)

29. P. Hinsinger, A. G. Bengough, D. Vetterlein, and I. M. Young, Plant Soil, 321, 117 (2009)

30. D. B. Read, A. G. Bengough, P. J. Gregory, J. W. Crawford, D. Robinson, C. M. Scrimgeour, I. M. Young, K. Zhang, and X. Zhang, New Phytol., 157, 315 (2003) 